\title{
Isolation and Gain Enhancement Using Metamaterial Based Superstrate for MIMO Applications
}

\author{
Robert MARK ${ }^{1}$, Neha RAJAK ${ }^{2}$, Kaushik MANDAL $L^{3}$, Soma DAS ${ }^{1}$ \\ ${ }^{1}$ Dept. of ECE, Guru Ghasidas Vishwavidyalaya, (Central University), Bilaspur, India \\ ${ }^{2}$ Dept. of ECE, Birla Institute of Technology, Mesra, Ranchi, India \\ ${ }^{3}$ Institute of Radio Physics and Electronics, University of Calcutta, India
}

mark.robert.1989@ieee.org, rajakneha@gmail.com, kaushikrpe@gmail.com,soma.iitkharagpur@gmail.com

Submitted May 2, 2019 / Accepted August 13, 2019

\begin{abstract}
In this paper, a metamaterial superstrate inspired multiple-input-multiple-output (MIMO) for gain and isolation enhanced antenna system is investigated for WLAN applications. The superstrate layer generates a resonant cavity effect which results in gain enhancement of the antenna system by $3.73 \mathrm{dBi}$ (65\%). The superstrate consists of a novel hexagonal nested ring structure, placed at a height of $0.175 \lambda_{0}$ above antenna and confines the near field coupling between the antenna elements, thereby reducing the mutual coupling. The isolation between each antenna elements is better than $20 \mathrm{~dB}$ over the entire band of operation with reduced edge-to-edge spacing of $0.057 \lambda_{0}$ which makes it suitable for the larger MIMO configurations. The prototype of the proposed design is fabricated and validated through proper measurement that shows the measured impedance bandwidth of 7.0\% (5.65-6.06 GHz). The measured gain and simulated efficiency remains above $8.6 \mathrm{dBi}$ and $84 \%$ along with envelope correlation coefficient $<0.003$ over the operating band making the design suitable for high gain MIMO WLAN applications.
\end{abstract}

\section{Keywords}

Envelope Correlation Coefficient (ECC), isolation enhancement, metamaterial, Multiple-Input-MultipleOutput (MIMO)

\section{Introduction}

The need for speed along with high-quality data transmission within limited power levels has increased the exploitation of multiple-input-multiple-output (MIMO) antenna design in modern wireless systems [1]. A MIMO system incorporates a large number of individual excited antennas which results in increased performance in terms of data rates. However, implementation of multiple antennas in a limited design space is a major constraint due to the interelement coupling which reduces the antenna performances. In reported literatures, various design techniques have been implemented to principally reduce the mutual coupling in MIMO system such as with implemen- tation of stubs and neutralization lines [2], [3], split ring and complementary split ring resonators [4-6], polarization isolation converters [7], various parasitic resonant elements [8], [9], metamaterial based decoupling structure [10], [11] etc. In [12], a novel design utilizing frequency selective surface (FSS) based unconventional ground plane is demonstrated for simultaneous improvement of isolation and radar cross section (RCS) reduction in MIMO antenna. However, to improve gain performance of MIMO system along with reduction in mutual coupling, various metamaterial based designs offer a viable solution as they increase the gain of antenna system and also has the potential to meet the design requirement of reduced mutual coupling that lead us to explore the new possibilities of metamaterial based superstrate designs [13-15].

In this paper, we propose a metamaterial (MTM) based superstrate design for simultaneous improvement of both the isolation and gain performance of MIMO system. It is worth to mention that the proposed design offers significant mutual coupling reduction within reduced edgespaced antenna elements (increasing the packing density) and superstrate height space with such that the given design offers a better design option for WLAN applications compared to that of previous reported literatures. The proposed design is particularly reported to give a measured gain improvement of $3.73 \mathrm{dBi}$ with reduced edge-to-edge spacing of $0.057 \lambda_{0}$ so that it can be easily extended to high gain MIMO system with large elements without any changes in the original antenna. To validate the simulations results of the proposed design, the fabricated prototype is tested experimentally and a good agreement is observed.

\section{MIMO Design with MTM-based Superstrate}

Figure 1 illustrates the geometry and design parameters of the proposed four-element MIMO antenna and the decoupling metamaterial superstrate that are printed on a RT/Duroid $5870\left(\varepsilon_{\mathrm{r}}=2.33, \tan \delta=0.0012\right)$ of thickness $1.57 \mathrm{~mm}$ and RT/Duroid 5880 substrate $\left(\varepsilon_{\mathrm{r}}=2.2\right.$, $\tan \delta=0.0009$ ) of thickness $0.787 \mathrm{~mm}$, respectively. 

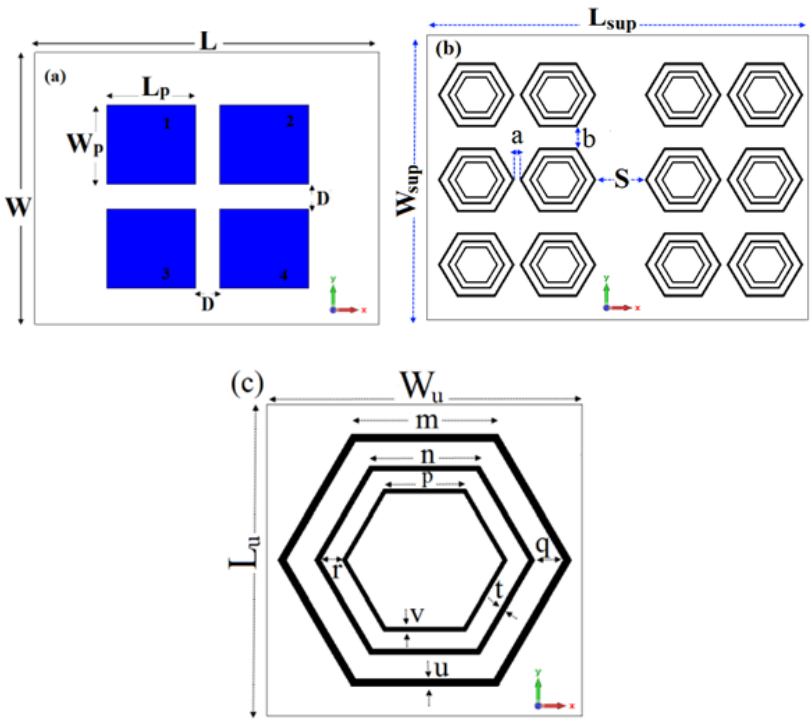

Fig. 1. (a) Top view of four port MIMO antenna. (b) Top views of superstrate geometry. (c) Top view of metamaterial unit cell. The design parameters (Units in: $\mathrm{mm}): \mathrm{L}=70, \mathrm{~W}=60, \mathrm{~L}_{\mathrm{p}}=18, \mathrm{~W}_{\mathrm{p}}=16, \mathrm{~L}_{\text {sup }}=70$, $\mathrm{W}_{\text {sup }}=56, \mathrm{D}=3, \mathrm{a}=1, \mathrm{~b}=4$ and $\mathrm{S}=9, \mathrm{~L}_{\mathrm{U}}=\mathrm{W}_{\mathrm{U}}=15$, $\mathrm{m}=7, \mathrm{n}=5.25, \mathrm{p}=3.95, \mathrm{r}=1, \mathrm{q}=1.35, \mathrm{v}=0.25$ $\mathrm{u}=0.40$ and $\mathrm{t}=0.30$.

The proposed antenna is composed of four identical rectangular patches whose individual dimensions $\left(L_{\mathrm{P}} \times W_{\mathrm{P}}\right)$ $18 \times 16 \mathrm{~mm}^{2}$ are calculated and parametrically optimized so that it resonates at $5.7 \mathrm{GHz}$. The edge-to-edge separation (D) of $0.057 \lambda_{0}$ between the patches is fixed for the best performance of the antenna. Each antenna element is excited using a coaxial probe feed with an offset distance of $4 \mathrm{~mm}$ from center of the patch. The basic design of MTM unit cell consists of hexagonal ring resonators loop in a nested structure, where the radius and width of individual hexagon rings are optimized to obtain desired electromagnetic properties near the resonance of the designed antenna. So the dimensions of the MTM rings are parametrically optimized to obtain high reflection and transmission characteristics near $6 \mathrm{GHz}$ frequency. During the optimization, with the increase of the width of the ring, the resonance properties of the metamaterial rings shift to higher frequency side. Hence, the width is also individually optimized to obtain the desired performance. The symmetrical hexagonal rings, due to simplicity of their structure, also offer as a path where currents linked to each ring traverse in opposing direction, which nullifies the effect of near field coupling. The decoupling superstrate consists of a finite number of unit cells arranged in an array of $(4 \times 3)$ configuration such that the superstrate area remains smaller than the MIMO antenna and design can be easily generalized for large elements MIMO. Figure 1(b) shows the MTM superstrate with no copper on bottom side of the superstrate. The metamaterial unit cell is simulated in CST Microwave Studio ${ }^{\mathrm{TM}}$ (CST) under proper boundary conditions to obtain the reflection $\left(S_{11}\right)$ and transmission $\left(S_{21}\right)$ coefficient, which are further used to extract effective material parameters (permeability and permittivity) using the algorithm as described in [16], [17]. Figure 2(a) shows the
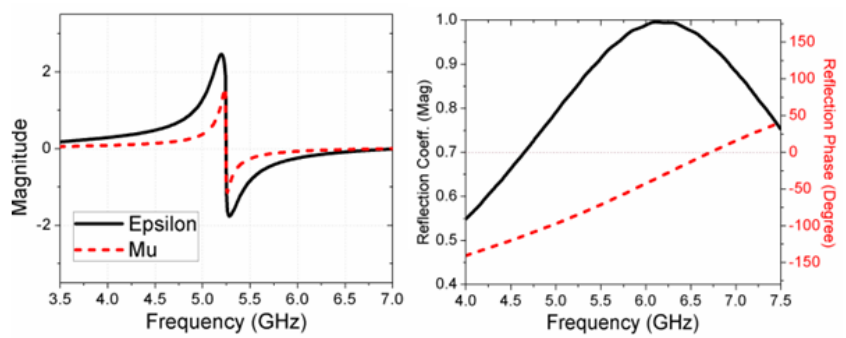

Fig. 2. (a) Extracted metamaterial parameters.

(b) Performance of the proposed unit cell.

extracted parameters of the unit cell that shows both the relative permeability and permittivity are negative in the desired frequency band $(5.25-6.8 \mathrm{GHz})$ which justifies the condition that the proposed unit cell is acting as a lefthanded material (LHM). As shown in Fig. 2(b) the unit cell exhibits high reflection magnitude over the desired band and flat reflection phase. These properties of the proposed superstrate ensure that the gain of the antenna can be increased significantly as the reflection magnitude increases to unity [18].

The superstrate designed using the proposed unit cell acts as a high reflective lens to focus the propagating waves in a directive pattern thereby increasing the broadside gain of the antenna. The antiparallel current path over the unit cell of hexagonal rings is the major reason for the nullification of near field coupling in the structure (Fig. 5). The superstrate along with antenna is simulated and optimized, where the periodicity between the unit cells in superstrate is optimized to obtain an ideal design for both gain and isolation enhancement. The designed superstrate is shown in Fig. 1(b), where rows of unit cells are separated by a spacing, $b=0.076 \lambda_{0}$ for better isolation performance of the antenna. The superstrate is kept at a height $H=0.175 \lambda_{0}$ above the patch antenna using four hollow plastic rod supports at the four corners of the system as shown in Fig. 7(c). Figure 3 shows the simulated S-parameters of the system when antenna 1 is excited. In presence of superstrate, the resonance is shifted from 5.7 to $5.85 \mathrm{GHz}$ due to air layer in between the superstrate and antenna. The antenna exhibits $\left|S_{11}\right|<-10 \mathrm{~dB}$ impedance bandwidth of $0.41 \mathrm{GHz}(7.0 \%)$ at $5.85 \mathrm{GHz}$ with isolation level also remaining above $20 \mathrm{~dB}$ over the entire operating band for all antenna elements. The simulation results at resonating frequency show $22 \mathrm{~dB}\left(S_{21}=6\right.$ to $\left.28 \mathrm{~dB}\right)$ isolation improvement between antenna 1 and 2 and approx. $20 \mathrm{~dB}$ improvement between diagonal antenna elements from $\left(S_{31}=8 \mathrm{~dB}\right.$ to $28 \mathrm{~dB}$ and $S_{41}=9 \mathrm{~dB}$ to $\left.29 \mathrm{~dB}\right)$ as shown in Fig. 3 (inset).

The radiation patterns of the antenna with and without superstrate are compared in Fig. 4 when antenna 1 is excited. The effect of superstrate is direction independence in H-plane. However concentration of field, mostly to the nearest unit cell above the antenna, excited in a sequence with neighboring cells at different phases (as shown in Fig. 5(b)) causes radiated beam to steer by $\pm 25^{\circ}$ in direction of radiation of excited antenna. 


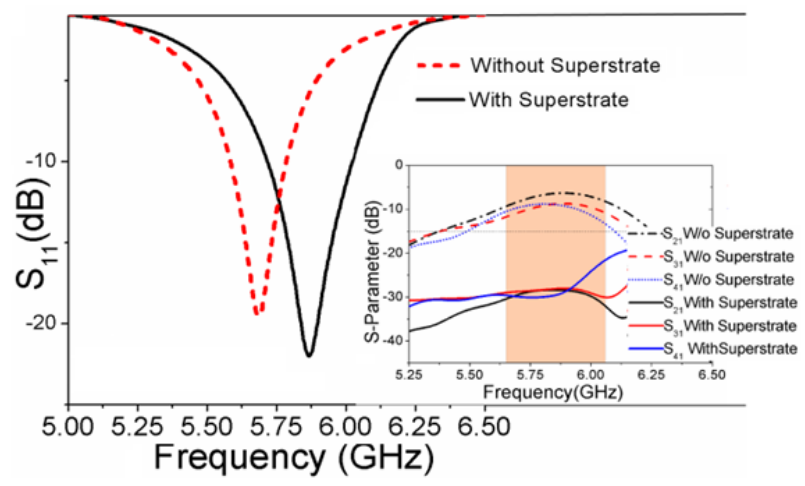

Fig. 3. Simulated S-parameter $\left(S_{11}\right)$ of the proposed MIMO antenna with and without (W/o) superstrate (Inset shows $S_{21}, S_{31}$ and $S_{41}$ ).

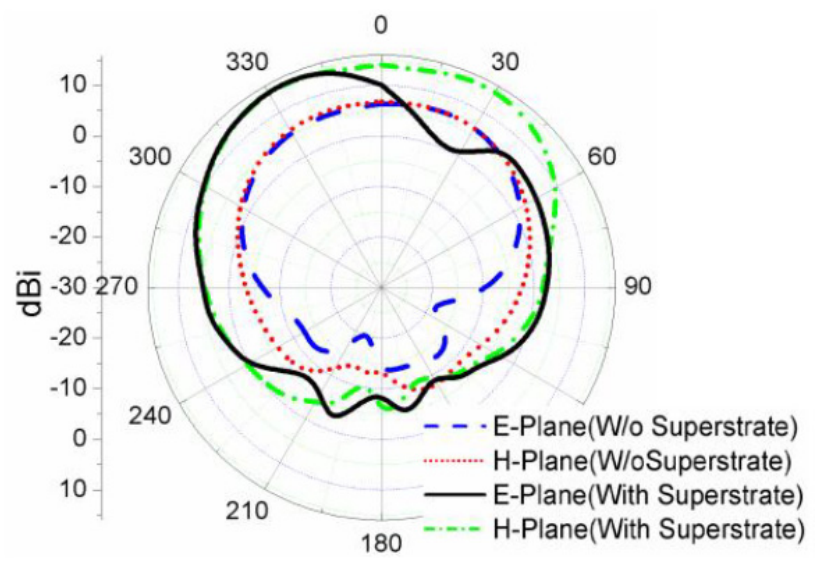

Fig. 4. Simulated radiation patterns of the proposed MIMO antenna 1 with and without (W/o) superstrate in Eplane and H-plane.

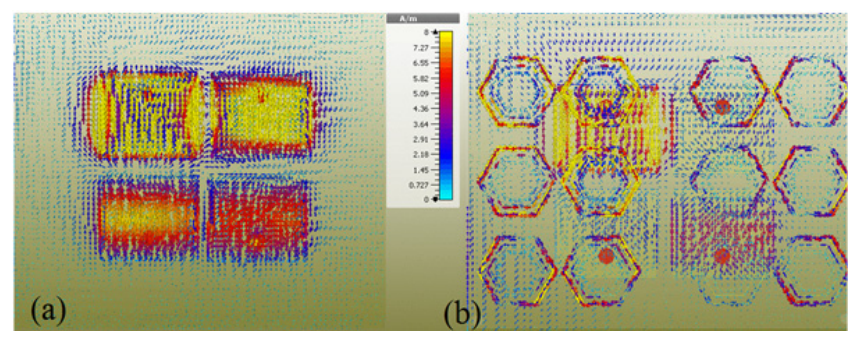

Fig. 5. Surface current distribution: (a) Without superstrate, (b) with superstrate.

Figure 5 shows the surface current distribution of the proposed MIMO antenna in order to validate the effect of superstrate structure for reduction of mutual coupling. The current distributions on the hexagon rings showed that the current coupled to each unit cell ring traverses in opposite direction in half of the ring as well as in adjacent rings, which nullifies the effect of near-field coupling. It can be seen from the analysis that in absence of superstrate when antenna 1 (top-left side) is excited and other antenna elements are terminated using $50 \Omega$ matched load, the surface current is distributed mainly on the center portion of antenna 2 (right side) and antenna 3 (bottom-left) with maximum radiation occurring from the side of the antenna (Fig. 5(a)). Therefore, mutual coupling due to excitation of antenna 1 occurs mostly on antenna 2 and then on an- tenna 3 and 4. Comparatively lower mutual coupling is present on antenna 4 . With superstrate structure placed above, the coupled field between antenna elements is concentrated mainly on the unit cell surface of superstrate thereby nullifying the coupling field and improving the isolation between antenna elements significantly.

\section{Parametric Study}

A parametric study has been done on two design parameters i.e. the height $H$ of MTM superstrate above patch and spacing $b$ between the rows of unit cells to find an optimum design so as to reduce the reflection coefficient $S_{21}, S_{31}, S_{41} \leq-15 \mathrm{~dB}$. The effect of spacing $b$ between the unit cells in superstrate structure is studied to obtain maximum gain along with reduced mutual coupling so as to derive the final configuration of superstrate structure suitable for MIMO configuration.

\subsection{Height of Superstrate from the Antenna Surface $H$}

The given design is simulated for different height of superstrate, $H$ to examine its effect on the S-parameter. As shown in Fig. 6(a), by increasing the height above $10 \mathrm{~mm}$ impedance matching of antenna starts to degrade at the resonance frequency. Whereas, when we shift the superstrate below $H=9 \mathrm{~mm}$, the resonance shifts toward a higher frequency side. However, interelement coupling $\left(S_{21}, S_{31}\right.$ and $\left.S_{41}\right)$ remain below $-15 \mathrm{~dB}$ for any range of height $H$. Thus the height of superstrate is optimized and fixed at $9 \mathrm{~mm}$ for the largest impedance bandwidth as shown in the shaded area so as to cover the required WLAN frequency band. Similarly, the effect of height of superstrate on gain is studied as shown in Fig. 6(b). It shows that the gain of system is maximum for $H=9 \mathrm{~mm}$. The gain of system decreases with the increase of $H$. With lower height of superstrate $(H=5 \mathrm{~mm})$, there is increment in the gain of system however, there is a large shift in resonance frequency (Fig. 6 (a)) as well as a low impedance bandwidth is observed. Hence, the height of superstrate is fixed at $H=9 \mathrm{~mm}$ for the best performance of MIMO.

\subsection{Spacing $b$ between the Rows of Unit Cells}

The variations in antenna gain due to change in gap $b$ between the rows of unit cells when height of superstrate is fixed at $H=9 \mathrm{~mm}$ is studied and plotted in Fig. 6(c). It shows that with the increase of distance $b$ between the rows of unit cell, the gain of MIMO system will start to decrease in the entire frequency band. However, the change in spacing $b$ causes less variation in mutual coupling (i.e. change in $S_{21}, S_{31}$ and $S_{41}$ ) within $\pm 5 \mathrm{~dB}$ range. At spacing of $b=4 \mathrm{~mm}$ the simulated gain of the antenna obtained is the highest at operating bandwidth. Thus, spacing between unit cells is fixed at $4 \mathrm{~mm}$ to obtain the best performance of MIMO antenna. 

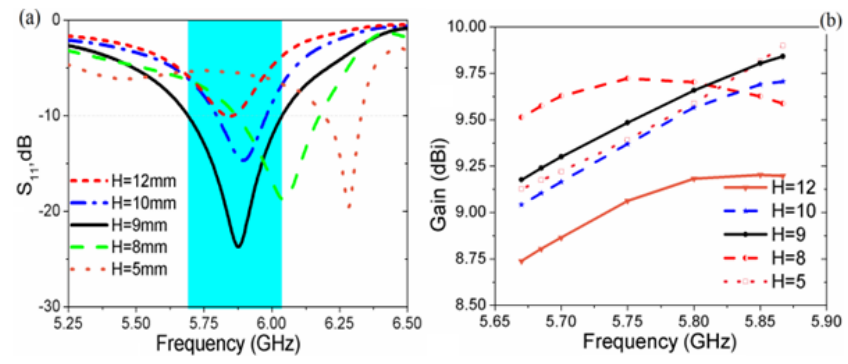

(c)

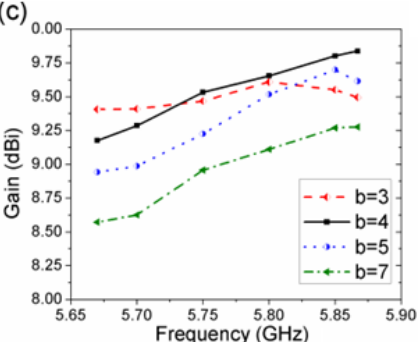

Fig. 6. (a) Simulated results of $S_{11}$ for different values of height $H$. (b) Simulated antenna gain for varying height of superstrate $H$ for spacing $b=4 \mathrm{~mm}$ (constant). (c) Simulated antenna gain for different values of unit cell separation $b$ at height $H=9 \mathrm{~mm}$ (constant).

\section{Simulated and Measured Results}

To validate the simulation results, a prototype of the proposed design is fabricated and measured using Agilent (N5230A) network analyzer as shown in Fig. 7(a), (b). The gain and radiation patterns of the antenna are calculated in a controlled laboratory environment using the proper measuring techniques as shown in Fig. 7. The measured results are presented when antenna 1 is excited and the remaining is terminated with $50 \Omega$ matched load. The same is also true when other antennas are excited under identical conditions due to the symmetry of design. The measured Sparameter shows a good agreement with simulated one and has an operating impedance bandwidth of $7 \%(5.65 \mathrm{GHz}$ to $6.06 \mathrm{GHz}$ ) as shown in Fig. 8. The measured isolation between the various antenna elements is well above $21 \mathrm{~dB}$ over the entire operating band with peak isolation of $S_{21}=41 \mathrm{~dB}$ at $5.84 \mathrm{GHz}$. The measured result implies that the proposed antenna meets the impedance bandwidth along with the isolation requirement suitable for $5.8 \mathrm{GHz}$ WLAN applications. The measurement of the radiation patterns in Fig. 9 shows the normalized 2-D radiation pattern of the antenna in both yz-plane (E-plane) and xz-plane (H-plane) at $5.85 \mathrm{GHz}$ with $-25^{\circ}$ shifts in main beam pattern corresponding to broadside direction in E-plane.

For H-plane, the pattern remains almost unaltered in the measurement as that of the simulation. The gain of the antenna is measured with and without MTM superstrate and is plotted in Fig. 10(a) for comparison. A maximum gain of $9.49 \mathrm{dBi}$ at $5.85 \mathrm{GHz}$ is obtained which is $3.73 \mathrm{dBi}$ higher compared to that without MTM. The simulated total efficiency of the antenna (Fig. 10(b)) remains above $84 \%$ over the desired band of operation with maximum efficiency $88 \%$ at $5.85 \mathrm{GHz}$.

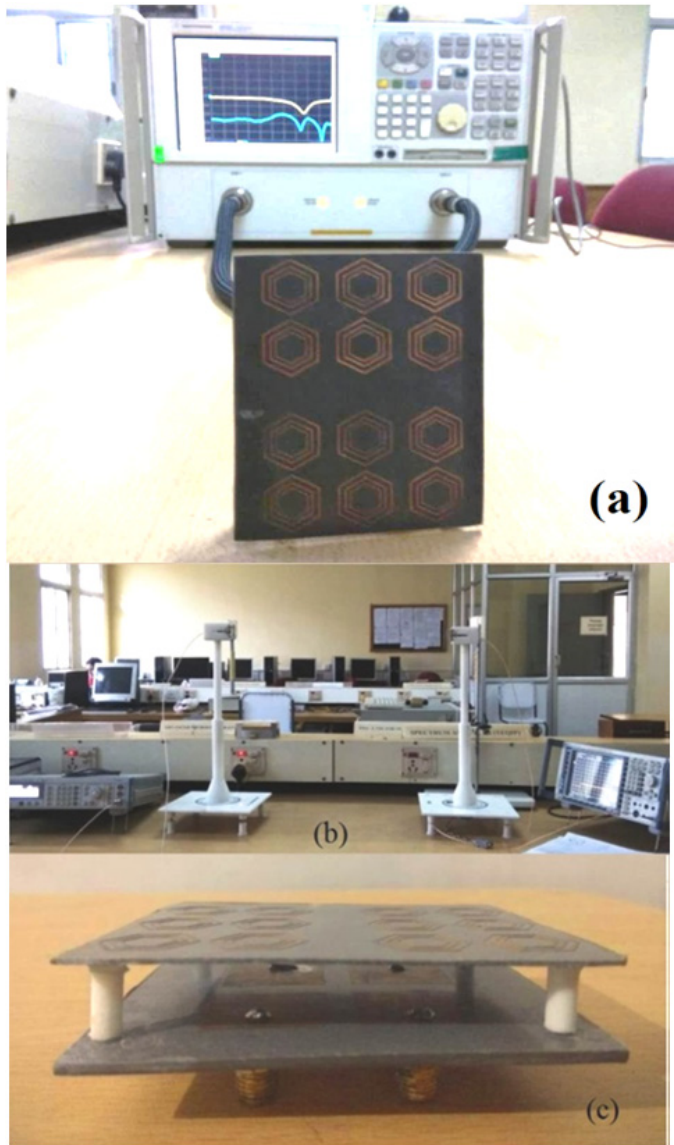

Fig. 7. Prototype of the fabricated antenna: (a) Under measurement. (b) Measurement setup. (c) Perspective view.

(a)
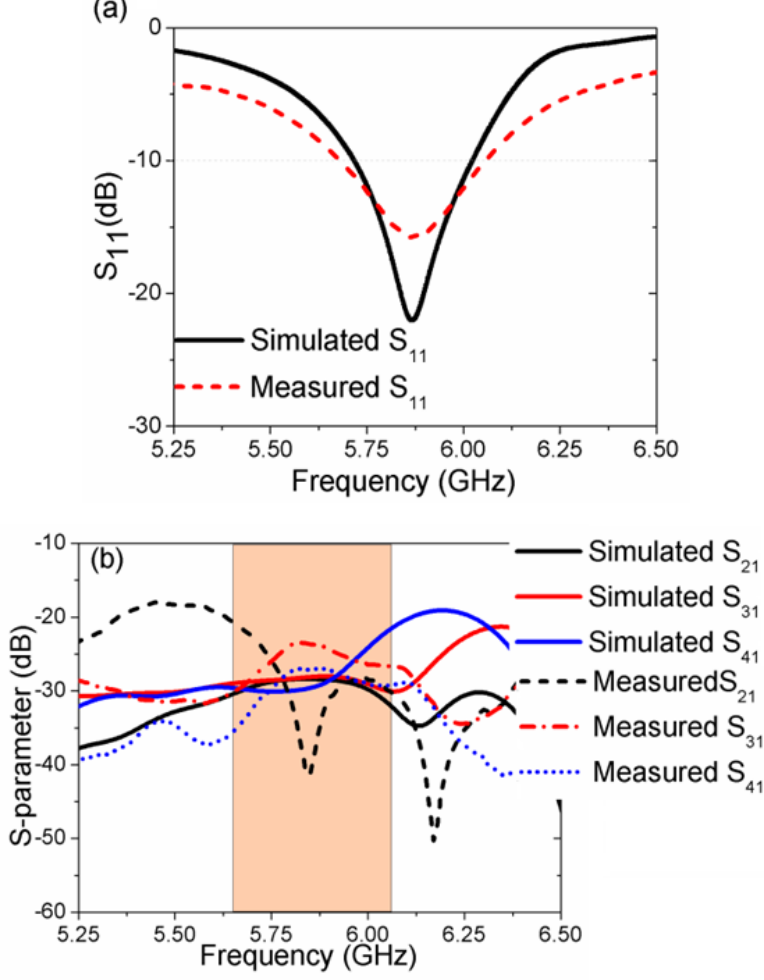

Fig. 8. Simulated and measured S-parameters: (a) $S_{11}$, (b) $S_{21}$, $S_{31}$ and $S_{41}$ of the proposed MIMO antenna with superstrate. 


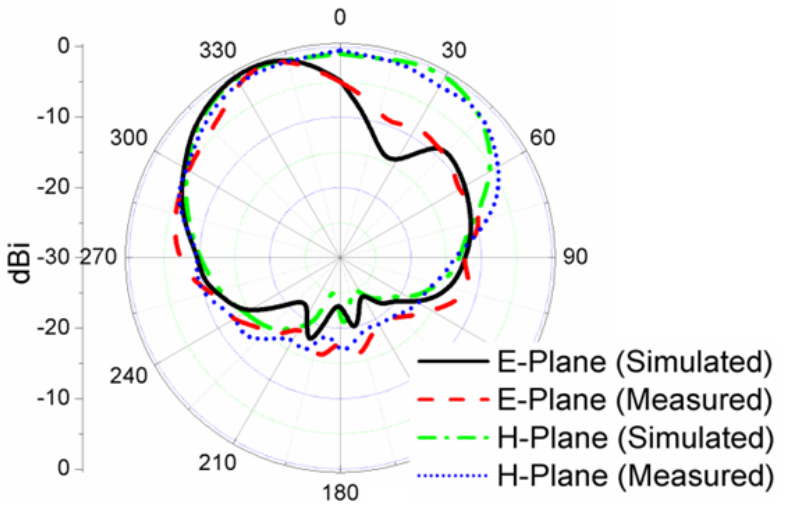

Fig. 9. Simulated and measured normalized far field radiation patterns of the proposed MIMO antenna with superstrate.

(a)

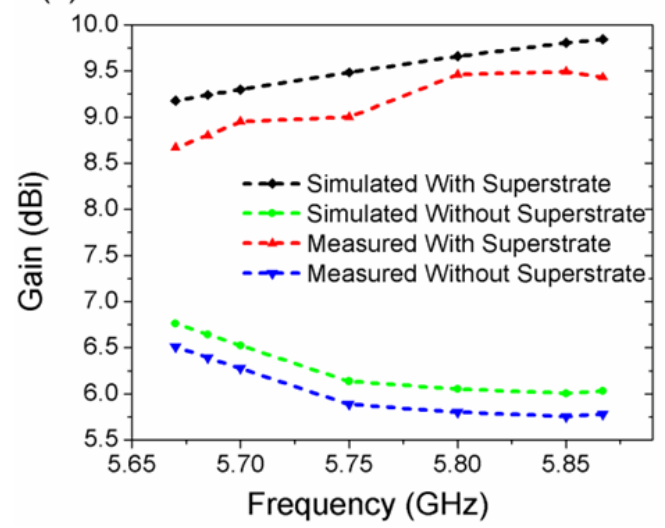

(b)
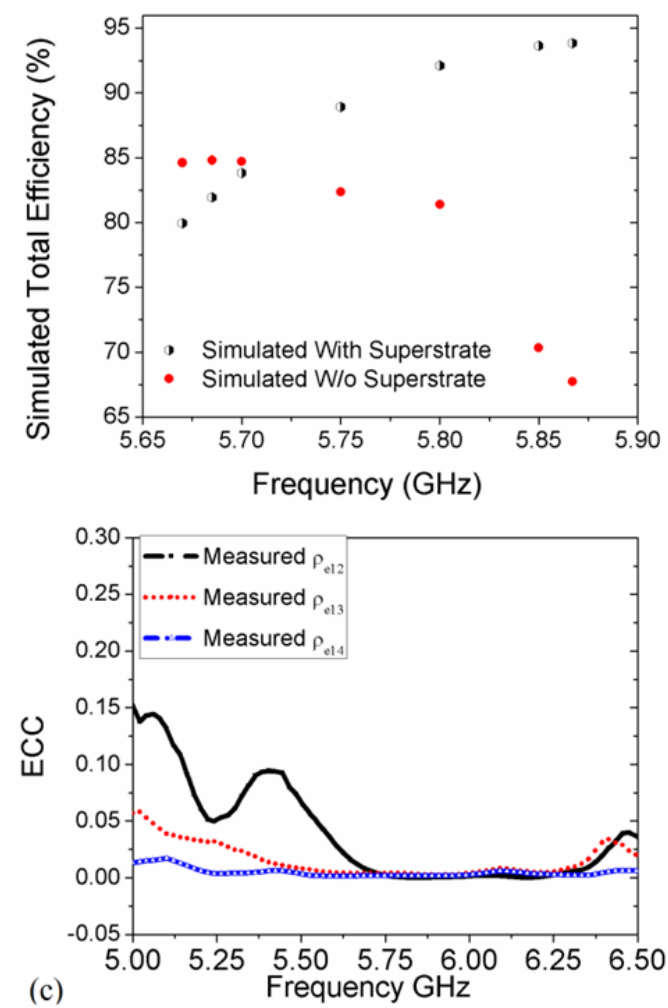

Fig. 10. (a) Simulated and measured gain. (b) Simulated total efficiency of the proposed MIMO. (c) Measured ECC.
The diversity performance of MIMO defined in terms of Envelope Correlation Coefficient. (ECC) provides the degree of signal correlation between each antenna elements. ECC $\left(\rho_{\mathrm{e}}\right)$ is the measure of diversity performance of antenna which is calculated from far field patterns of the individual antennas [10] or from S-parameters [1], [2]. Here, ECC is calculated from S-parameters and is obtained well below 0.003 as shown in Fig. 10(c), which satisfies the good diversity performance $(\mathrm{ECC}<0.5)$ of MIMO antenna. The performance of the proposed MIMO is compared with earlier designs in terms of isolation techniques, isolation improvement and edge-to-edge spacing between antenna elements along with the observed gain and efficiency and is summarized in Tab. 1. It shows that the proposed design offers a novel design technique where metamaterial based superstrate is utilized to enhance both the gain and isolation of a MIMO. The reduced inter element spacing as well as narrow edge-to-edge spacing between the radiating elements along with improved gain are the main advantages of the proposed MIMO design and can be easily extended for large size high gain MIMO structure.

\section{Conclusion}

In this paper, a novel MTM based superstrate design for both high gain and isolation enhanced MIMO system is investigated and proposed. The design offers a small edgeto-edge spacing of $0.057 \lambda_{0}$ with measured isolation level between each antenna elements remaining above $21 \mathrm{~dB}$ over the entire operating band with peak isolation of $41 \mathrm{~dB}$ at $5.84 \mathrm{GHz}$. The design also shows a significant gain enhancement of $3.73 \mathrm{dBi}$ over the desired frequency band. The impact of MTM superstrate height and unit cell spacing on mutual coupling reduction and antenna gain is studied. The proposed design offers novelty in terms of a superstrate based decoupling MTM structure that increases both gain and isolation of MIMO simultaneously. The antenna covers $5.65-6.06 \mathrm{GHz}$ frequency band with ECC values less than 0.003 making the design suitable for $5.8 \mathrm{GHz}$ WLAN applications. The design is verified for four-port antennas and can be simply extended to higher element MIMO design.

\section{References}

[1] SHARAWI, M. S. Printed multi-band MIMO antenna systems and their performance metrics. IEEE Antennas and Propagation Magazine, 2013, vol. 55, no. 5, p. 218-232. DOI: 10.1109/MAP.2013.6735522

[2] IQBAL, A., SARAEREH, O. A., AHMAD, A. W., et al. Mutual coupling reduction using F-shaped stubs in UWB-MIMO antenna. IEEE Access, 2017, vol. 6, p. 2755-2759. DOI: 10.1109/ACCESS.2017.2785232

[3] SU, S. W., LEE, C. T., CHANG, F. S. Printed MIMO-antenna system using neutralization-line technique for wireless USBdongle applications. IEEE Transactions on Antennas and Propagation, 2012, vol. 60 , no. 2, p. 456-463. DOI: 10.1109/TAP.2011.2173450 


\begin{tabular}{|c|c|c|c|c|c|c|c|c|}
\hline Ref & $\begin{array}{l}\text { Isolation reduction } \\
\text { technique }\end{array}$ & $\begin{array}{c}\text { Center } \\
\text { frequency } \\
f_{0} \\
(\mathrm{GHz})\end{array}$ & $\begin{array}{l}\text { Edge to edge } \\
\text { spacing } \\
\text { (mm) }\end{array}$ & $\begin{array}{l}\text { Peak } \\
\text { isolation } \\
\text { (dB) }\end{array}$ & $\begin{array}{l}\text { Isolation } \\
\text { enhancement } \\
\text { (dB) }\end{array}$ & $\begin{array}{c}\text { Gain } \\
\text { (Increase in } \\
\text { gain) } \\
(\mathrm{dBi})\end{array}$ & $\begin{array}{c}\text { Simulated } \\
\text { efficiency } \\
(\%)\end{array}$ & $\begin{array}{l}\text { Height of } \\
\text { superstrate } \\
\quad(\mathrm{mm})\end{array}$ \\
\hline [10] & $\begin{array}{c}\text { Frequency selective } \\
\text { surface }\end{array}$ & 5.25 & $\begin{array}{c}7.43 \\
\left(0.13 \lambda_{0}\right)\end{array}$ & 20 & --- & $\begin{array}{c}9 \\
(---)\end{array}$ & $>91.7$ & $\begin{array}{c}14 \\
\left(0.25 \lambda_{0}\right)\end{array}$ \\
\hline [12] & $\begin{array}{c}\text { Frequency selective } \\
\text { surface }\end{array}$ & 4.35 & $\begin{array}{c}10 \\
\left(0.145 \lambda_{0}\right) \\
\end{array}$ & 28 & 18 & $\begin{array}{c}4.8 \\
(---)\end{array}$ & $>75$ & ------ \\
\hline [13] & $\begin{array}{l}\text { EMNZ metamaterial } \\
\text { superstrate }\end{array}$ & 2.6 & $\begin{array}{c}4 \\
\left(0.033 \lambda_{0}\right) \\
\end{array}$ & 30 & 15 & $\begin{array}{c}\text { Increase by } \\
(3.5)\end{array}$ & $>62$ & $\begin{array}{c}10 \\
\left(0.833 \lambda_{0}\right) \\
\end{array}$ \\
\hline [14] & $\begin{array}{l}\text { Metasurface } \\
\text { superstrate }\end{array}$ & 2.5 & $\left(0.27 \lambda_{0}\right)$ & 42 & 25 & $\begin{array}{c}\text { Increase by } \\
(2.5)\end{array}$ & $>87$ & $\begin{array}{c}15 \\
\left(0.125 \lambda_{0}\right)\end{array}$ \\
\hline [15] & $\begin{array}{c}\text { Capacitive loaded } \\
\text { loop metasurface } \\
\text { superstrate } \\
\end{array}$ & 3.3 & $\begin{array}{c}11.1 \\
\left(0.12 \lambda_{0}\right)\end{array}$ & 65 & 55 & $\begin{array}{l}(8.2) \\
(0.1)\end{array}$ & 97 & $\begin{array}{c}13.9 \\
\left(0.15 \lambda_{0}\right)\end{array}$ \\
\hline $\begin{array}{l}\text { Proposed } \\
\text { design }\end{array}$ & $\begin{array}{l}\text { DNG metamaterial } \\
\text { superstrate }\end{array}$ & 5.7 & $\begin{array}{c}3 \\
\left(0.057 \lambda_{0}\right)\end{array}$ & 41 & 22 & $\begin{array}{c}9.49 \\
(3.73)\end{array}$ & $>84$ & $\begin{array}{c}9 \\
\left(0.175 \lambda_{0}\right)\end{array}$ \\
\hline
\end{tabular}

Tab. 1. Comparison between the proposed designs with other MIMO antenna systems.

[4] HABASHI, A., NOURINIA, J., GHOBADI, C. Mutual coupling reduction between very closely spaced patch antennas using lowprofile folded split-ring resonators (FSRRs). IEEE Antennas and Wireless Propagation Letters, 2011, vol. 10, p. 862-865. DOI: 10.1109/LAWP.2011.2165931

[5] RAMACHANDRAN, A., PUSHPAKARAN, S. V., PEZHOLIL, M., et al. A four-port MIMO antenna using concentric square-ring patches loaded with CSRR for high isolation. IEEE Antennas and Wireless Propagation Letters, 2015, vol. 15, p. 1196-1199. DOI: 10.1109/LAWP.2015.2499322

[6] WEI, K., LI, J. Y., WANG, L., et al. Microstrip antenna array mutual coupling suppression using coupled polarization transformer. IET Microwaves, Antennas and Propagation, 2017, vol. 11, no. 13, p. 1836-1840. DOI: 10.1049/iet-map.2016.1154

[7] CHENG, Y. F., DING, X., SHAO, W., et al. Reduction of mutual coupling between patch antennas using a polarization conversion isolator. IEEE Antennas and Wireless Propagation Letters, 2016, vol. 16, p. 1257-1260. DOI: 10.1109/LAWP.2016.2631621

[8] ARUN, H., SARMA, A. K., KANAGASABAI, M., et al. Deployment of modified serpentine structure for mutual coupling reduction in MIMO antennas. IEEE Antennas and Wireless Propagation Letters, 2014, vol. 13, p. 277-280. DOI: 10.1109/LAWP.2014.2304541

[9] VISHVAKSENAN, K. S., MITHRA, K., KALAIARASAN, R., et al. Mutual coupling reduction in microstrip patch antenna arrays using parallel coupled-line resonators. IEEE Antennas and Wireless Propagation Letters, 2017, vol. 16, p. 2146-2149. DOI: 10.1109/LAWP.2017.2700521

[10] HASSAN, T., KHAN, M. U., ATTIA, H., et al. An FSS based correlation reduction technique for MIMO antennas. IEEE Transactions on Antennas and Propagation, 2018, vol. 66, no. 9, p. 4900-4905. DOI: 10.1109/TAP.2018.2842256

[11] DADGARPOUR, A., ZARGHOONI, B., VIRDEE, B. S., et al. Mutual coupling reduction in dielectric resonator antennas using metasurface shield for $60-\mathrm{GHz}$ MIMO systems. IEEE Antennas and Wireless Propagation Letters, 2016, vol. 16, p. 477-480. DOI: 10.1109/LAWP.2016.2585127

[12] THUMMALURU, S. R., KUMAR, R., CHAUDHARY, R. K. Isolation enhancement and radar cross section reduction of MIMO antenna with frequency selective surface. IEEE Transactions on Antennas and Propagation, 2018, vol. 66, no. 3, p. 1595-1600. DOI: 10.1109/TAP.2018.2794417

[13] PANDA, P. K., GHOSH, D. Isolation and gain enhancement of patch antennas using EMNZ superstrate. AEU-International Journal of Electronics and Communications, 2018, vol. 86, p.164-170. DOI: 10.1016/j.aeue.2018.01.037
[14] LIU, F., GUO, J., ZHAO, L., et al. A meta-surface decoupling method for two linear polarized antenna array in sub- $6 \mathrm{GHz}$ base station applications. IEEE Access, 2018, vol. 7, p. 2759-2768. DOI: 10.1109/ACCESS.2018.2886641

[15] JAFARGHOLI, A., JAFARGHOLI, A., CHOI, J. H. Mutual coupling reduction in an array of patch antennas using CLL metamaterial superstrate for MIMO applications. IEEE Transactions on Antennas and Propagation, 2019, vol. 67, no. 1, p. 179-189. DOI: 10.1109/TAP.2018.2874747

[16] ASHRAF, F. B., ALAM, T., ISLAM, M. T. A uniplanar lefthanded metamaterial for terrestrial microwave links. IEEE Microwave and Wireless Components Letters, 2018, vol. 28, no. 2, p. 108-110. DOI: 10.1109/LMWC.2017.2784680

[17] SZABO, Z., PARK, G. H., HEDGE, R., et al. A unique extraction of metamaterial parameters based on Kramers-Kronig relationship. IEEE Transactions on Microwave Theory and Techniques, 2010, vol. 58, no. 10, p. 2646-2653. DOI: 10.1109/TMTT.2010.2065310

[18] ASAADI, M., AFIFI, I., SEBAK, A. R. High gain and wideband high dense dielectric patch antenna using FSS superstrate for millimeter-wave applications. IEEE Access, 2018, vol. 6, p. 38243-38250. DOI: 10.1109/ACCESS.2018.2854225

\section{About the Authors...}

Robert MARK received his B.E. degree in Electronics Engineering (2010) from Chhattisgarh Swami Vivekananda Technical University, Bhilai, India and M.Tech. Degree in Microwave Engineering (2014) from Madhav Institute of Technology \& Science, Gwalior, India. He is currently working towards the Ph.D. degree in Electronics Engineering from Institute of Technology, Guru Ghasidas Vishwavidyalaya, (Central University), Bilaspur, India. His research interests include fractal multiband and wideband antenna, metamaterial based MIMO antenna for wireless applications.

Neha RAJAK received her B.Tech. degree in Electronics and Communication Engineering (2011) from Shobhit Institute of Technology, Meerut, India and M.E Degree in Wireless Communication (2014) from Birla Institute of Technology, Mesra, and Ranchi, India. She is currently working towards the Ph.D. degree in Electronics and Communication Engineering from Birla Institute of Technol- 
ogy, Mesra, Ranchi, India. Her current research interests include metamaterial based antenna.

Kaushik MANDAL received his B.Sc. degree in Physics, B.Tech. and M.Tech. degree in Radio Physics and Electronics from the University of Calcutta, in 2001, 2004 and 2006 respectively. He received his Ph.D. (Tech.) from the University of Kalyani, in July 2014. From 2016 he is working as an Assistant Professor in the Institute of Radio Physics and Electronics, University of Calcutta, West Bengal, India. He has authored or co-authored over 25 internationally refereed journal and conference papers. His current research interests include the characterization and application of DGS, antennas for RF energy harvesting system, SIW integrated microstrip antenna, and performance enhancement of microstrip antenna using frequency selective surface (FSS). Dr. Mandal is a co-recipient of the IEEE TENCON 2017 Best Paper Award (in the track 'Antenna').
He is an active reviewer of IEEE Transactions on Antennas and Propagation, IEEE Antennas and Propagation Magazine, IET Microwaves Antennas \& Propagation, Progress in Electromagnetics Research (PIER) Journal, and AEU International Journal of Electronics and Communications.

Soma DAS received the B.Tech. in Instrumentation and Electronics Engineering and M.Tech. in Electronics and Telecommunication Engineering from Jadavpur University, 1998 and 2001 and Ph.D. from the Indian Institute of Technology, Kharagpur, India in 2007. From 2008 to 2012, she was a Post-Doctoral Researcher with University of Aveiro, Portugal. She is currently working as Assistant-Professor, Department of Electronics and Communication Engineering, Guru Ghasidas Vishwavidyalaya, (Central University), Bilaspur, India. Her research area includes MIMO antennas, spintronics, thin film multiferroics, magnetic-nanoparticles. 